\title{
Fundamental Elements for Sustainable Design
}

\author{
Faizah Mohammed Bashir ${ }^{1 *}$, Mohd Hamdan Ahmad², Amina Usman Sale ${ }^{3}$, \\ Aliyu Abdullahi ${ }^{4}$ and Ahmed Sani Aminu ${ }^{4}$ \\ 'Department of Architecture, University Technology Malaysia, Skudai - 81310, Malaysia; \\ faizahbash@yahoo.com \\ ${ }^{2}$ Institute Sultan Iskandar, University Technology Malaysia, Skudai - 81310, Malaysia; \\ b-hamdan@utm.my \\ ${ }^{3}$ Faculty of Technology Management and Business, University Tun Hussein Onn Malaysia, Batu Pahat, Malaysia; \\ babymina90@yahoo.com \\ ${ }^{4}$ Department of Architecture, Faculty of Built Environmental, Ahmadu Bello University, Zaria Kaduna State, \\ Nigeria; aliyuabdullahi58@yahoo.com, asaminu@gmail.com
}

\begin{abstract}
Objective: The study extract the fundamental elements needed for sustainable design considering fourteen (14) countries. Methods/Statistical Analysis: The study examined the elements used in different assessment tools for 14 countries, and found out the most used elements which almost all the assessment tools used them based on critical analysis. Findings: From the assessment tools five (5) most used elements were identified which are very important to sustainable design. Application/Improvement: In conclusion sustainable design will not be effective if any of the five (5) elements is eliminated, because it shows that for design to be effectively sustainable the 5 elements need to be included.
\end{abstract}

Keywords: Assessment Tools, Elements, Environmental Friendly, Fundamental, Sustainable Design

\section{Introduction}

Sustainable design covers not only environmental considerations, but also integrates environmental issues with cost, schedule, operations, maintenance, and worker/employee considerations. Furthermore, sustainable design tries to decrease negative effects on the environment, comfort and health of buildingoccupants, by refining building performance $\stackrel{1}{ }$. Sustainable designs attempt to maximize complete efficiency through immediate resources, like transportation, along with energy efficiency, habitat conservation and renewal, natural and renewable energy sources, recycled local and non-toxic materials, water conservation, healthy and productive indoors $\underline{2}$. From the above, it suggests that sustainable design is not an option but a necessity; because sustainable community repairs, reserves, and improves environment and values for the advantage of all life present-day and upcoming. A diverse and healthy environment is basically valuable and important to a healthy community; but today, people are seriously corrupting the environment and the environment is not sustainable ${ }^{3}$.

There are many elements in sustainable design to be considered to make a building sustainable or green. So, this study aims to extract the fundamental elements needed for sustainable design which will help a building to be considered sustainable. 


\subsection{Sustainable Design}

Sustainable design can encourage healthier, comfortable, well-being, and activeness of building occupants, which can cut down altitudes of absence and increase productivity in offices ${ }^{4}$. Features of Sustainable building can compromise owners economic welfares of longer lifetimes of building, better-quality to draw more employees, lower risks, reduced costs for dealing with complaints, less time and lower expenses for project approving subsequent acceptance and support from community for sustainable projects, and increased ability value $\mathrm{e}^{-}$. Describes ${ }^{6}$ sustainable design as design and build that considerably lessen the undesirable effect of buildings on the surroundings plus its occupiers in 5 (five) general parts: site location, water, energy, materials and resources conservation and indoor environmental quality.

\subsection{Importance of Sustainable Buildings}

The following are the importance of sustainable buildings, the buildings should:

- Save energy- the buildings should be energy-efficient.

- Recycle buildings- use already built buildings and structure as an alternative of emerging new ones.

- Produce society- plan societies to lessen dependency on automobiles and to nurture intelligence of society.

- Use less material- the design should be improve so as to make use of less spaces and materials as well.

- Guard and develop the location- bring back local environments and biodiversity.

- Low-impact resources should be selected: require low environmental effect, supply good resources.

- Durability should be maximized- Plan for stability and flexibility.

- Use of water should be at minimal- the buildings and landscapes should use less water.

- Plan for healthy buildings- the indoor environment should be safe for the occupants.

- Demolition should be minimal and construction should be maximal- reduce, recycle, and reuse, waste, and make your project environmental friendly.
- "Green up" your projects- reduce the negative effect on environment, and save the word ${ }^{3}$.

\section{Method}

The study reviewed different green building rating tools for different countries as shown in Table 1 to extract the mostly used elements that are the most important elements for sustainable design.

Step 1- secondary data were gathered from internet, books and magazines

Step 2- theses data gathered were separated in to themes and categorize based on the WGBC- fundamental of sustainable design as delivered by ${ }^{7}$ definition of sustainability.

Step 3- Based on critical analysis technique as exemplified by ${ }^{8}$ Enegbuma 2011 the data was sorted out.

\section{Results and Discussion}

The result of the critical analysis was break down into different green building rating tools for different countries which are discussed briefly and the elements included.

\subsection{The International Sustainable Building/ Green Building Instrument System}

The SB Tool is a software method assessing the sustainability performance and environmental issues of buildings. It serves as an application of the Green Building Challenge (GBC) evaluation system, it was developed in 1996. The GBC practice was started by Natural Resources Canada, but International Initiative for a Sustainable Built Environment (IISBE) took over the responsibility in 2002. The system was applied at local scale then it became flexible of introducing benchmark standards permitting to the local ones. The system has two modules; Module A comprises benchmarks and weights which third parties can adjust to fit in the local settings, and Module B grades the sustainability condition of the building. The system is considered to be the general framework but the user can make changes if the need arise, which will add important 
Table 1. A comparison of international green building rating tools. Adopted from ${ }^{12}$

\begin{tabular}{|c|c|c|c|c|c|c|c|c|c|c|c|c|c|c|}
\hline S/NO. & 1 & 2 & 3 & 4 & 5 & 6 & 7 & 8 & 9 & 10 & 11 & 12 & 13 & 14 \\
\hline Country & 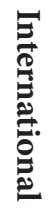 & 苞 & 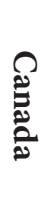 & 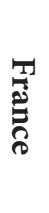 & 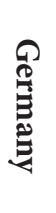 & $\begin{array}{l}\overrightarrow{\hat{\theta}} \\
\vec{\Xi}\end{array}$ & 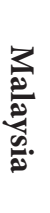 & 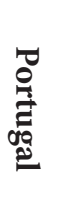 & 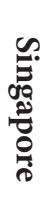 & 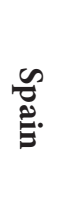 & $\underset{\pi}{C}$ & $\stackrel{S}{S}$ & $\begin{array}{c}E \\
\infty\end{array}$ & 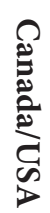 \\
\hline Tools & $\begin{array}{l}\stackrel{0}{0} \\
\mathscr{0} \\
\ddot{0} \\
\stackrel{0}{0}\end{array}$ & 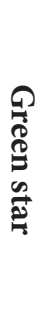 & 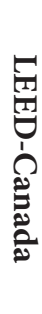 & 范 & 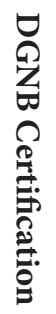 & $\begin{array}{l}\Omega \\
\mathbb{8} \\
\mathbb{W} \\
\text { M }\end{array}$ & 国 & $\begin{array}{l}5: \\
\frac{2}{2} \\
\frac{3}{2} \\
2\end{array}$ & 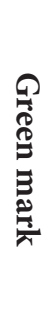 & 预 & 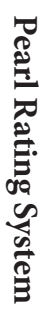 & 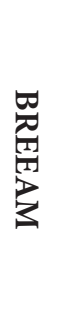 & 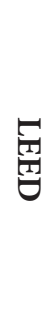 & 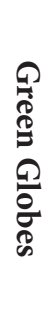 \\
\hline Sustainable site & $\star$ & & $*$ & $*$ & $\star$ & $\star$ & $*$ & $*$ & $*$ & $\star$ & $*$ & & $*$ & $*$ \\
\hline Energy efficiency & 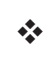 & $*$ & & $\star$ & $\nLeftarrow$ & $*$ & 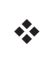 & $\star$ & $*$ & $\star$ & $\nLeftarrow$ & $*$ & $*$ & $*$ \\
\hline Water efficiency & $*$ & $\%$ & $*$ & 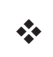 & $*$ & & $\star$ & $\star$ & $\star$ & 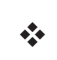 & $*$ & $*$ & $*$ & $*$ \\
\hline Indoor environmental & $*$ & $*$ & $*$ & $\star$ & 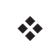 & $\star$ & $\star$ & 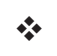 & $\star$ & 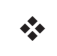 & 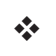 & 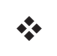 & $\nLeftarrow$ & 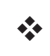 \\
\hline Materials and resources & $\star$ & $*$ & $*$ & $\star$ & 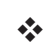 & 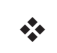 & $\star$ & $\star$ & & $\star$ & $*$ & 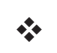 & $*$ & $*$ \\
\hline Land use and ecology & & $\star$ & & $*$ & $\%$ & $\star$ & $\star$ & $\star$ & & $\star$ & $*$ & $*$ & $*$ & $*$ \\
\hline Service quality & $\star$ & $*$ & & $\star$ & $*$ & $\star$ & & $\star$ & & 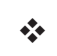 & $*$ & & & \\
\hline Transport & & $*$ & & & 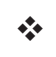 & & & & $\star$ & & 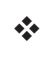 & 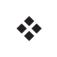 & $\nLeftarrow$ & \\
\hline Social aspect & $*$ & & & $\star$ & $\%$ & & & 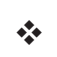 & & 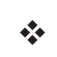 & $\nLeftarrow$ & $*$ & & \\
\hline Economic aspect & & & & & 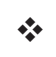 & & & & & $\star$ & $*$ & & & \\
\hline Cultural aspects & $\star$ & & & & $*$ & & & & & & $*$ & & & \\
\hline Regional priority & & & & & $\star$ & & & & & & $\star$ & & $*$ & 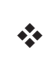 \\
\hline
\end{tabular}


Table 1 Continued

\begin{tabular}{|c|l|l|l|l|l|l|l|l|l|l|l|l|l|l|}
\hline Management & & & & $*$ & $*$ & & & & & $*$ & $*$ & $*$ & & \\
\hline $\begin{array}{c}\text { Innovation and design } \\
\text { Awareness and } \\
\text { education }\end{array}$ & & $*$ & $*$ & & $*$ & & $*$ & $*$ & $*$ & & $*$ & & $*$ & \\
\hline \begin{tabular}{c} 
Life cycle assessment \\
\hline
\end{tabular} & & & & & $*$ & & & $\star$ & & & $*$ & & & $*$ \\
\hline
\end{tabular}

rate of weights, benchmarks, and discharge values. The Benchmarks can be of numeric values, and the other in text form ${ }^{9,10}$. Measurement of -1 to +5 is used to express the assessment, where - 1 negative, 0 minimum acceptable practice, three (3) good performance and five (5) best performance. The criteria are:

- Sustainable site

- Water efficiency

- Materials and resources

- Energy efficiency

- Environmental loading

- Indoor environmental

- Social aspect

- Service quality

- Cultural aspects ${ }^{\underline{11}}$.

\subsection{The Green Star}

It was launched in 2003, it helps the property industry to lessen the environmental negative impact of buildings, fit outs and societies, increase resident wellbeing and efficiency and attain cost savings, even though showcasing novelty in sustainable building practices ${ }^{\frac{13}{3}}$.
- Green star criteria are:-

- Energy

- Indoor Environmental Quality

- Water

- Innovation

- Transport

- Land use and ecology

- Management

- Emission

- Materials $s^{\underline{14}}$.

\subsection{The Leadership in Energy and Environmental Design (LEED) method}

It was established by the US Green Building Council, there are parameters that are assessed to geta score, of gold, silver, and platinum certification. The LEED system includes many parties beside the procedure of the assessment and certifying or certification of the buildings. The LEED for homes supplier is a body that bring raters that deliver the homes certification of the construction and the performance analysis. The LEED experts are generally advisors connected to builders. 
- The LEED method parameters are:

- Sustainable sites

- Indoor environmental quality

- Energy and atmosphere

- Water efficiency

- Materials and resources

- Innovation and design process

- Homeowner awareness

- Environmental loading

- Regional priority

The LEED Situation Guide is an assessment method that ranks overall environmental performance of the buildings. It is distributed into environmental groupings which are important elements like $27 \%$ for energy and atmosphere, $23 \%$ for indoor environmental quality, $22 \%$ for sustainable sites, $20 \%$ for materials and resources, and $8 \%$ for water efficiency. The rating scale is classified into 4 levels in descending order of environmental sensitivity of 0-69 points. From 52 points or $>$ for platinum, gold is between $39-51$ points, while silver is between $33-38$ points, and 26-32 points for certified ${ }^{12}$.

\subsection{The High Quality Environmental standard (HQE) method}

The HQE was established in France and offers a typically vulnerable appeal. It incorporates a countless number of factors, which requires a method of running the processes stimulated by the international standard ISO 14001, also involves project practice unlike certification which is common in most of the other systems. Therefore, it has an exciting framework for exploiting practice responses, and for pursuing collective denominators. HQE came into existence in 1996, which let designers and project proprietors to implement construction choices suitable to environmental issues, at all steps of life cycle (from cradle to grave) of a building. The HQE Association stated14 goals requiring the specific requirements of environmental that a building must fulfill,
The application of HQE method needs some certain number of environmental issues, which are required.

- Energy that will be used for the whole life span of the building (energy used to building and energy that will be used by the owners, etc.);

- Water used in all stages of the building's life span;

- Waste that is produced by the building throughout its life cycle;

- Pollution and emission production in all stages of life span of the building; and

- The total cost the building will need for its life span, to make it healthier.

\subsection{The Comprehensive Assessment System for Built Environment Efficiency (CASBEE) system}

CASBEE is a Japanese environmental group system that evaluates building's environmental performance. CASBEE is established following three key ideas. First, is to assess the of buildings lifecycle. Second, is the main evaluation goal that differentiates environmental Load (L) and Quality of building performance (Q), Third, presents a new sign that is BEE (Building Environmental Efficiency) which is the idea of environmental friendly ${ }^{7}$. $\mathrm{BEE}$ is defined as $\mathrm{Q} / \mathrm{L}$ to specify the total outcome of buildings co-friendly evaluation, where

- $Q$ is then separated in three parts for evaluation:

- Q1, indoor environment;

- Q2, services quality; and

- Q3, site outdoor environment.

Also L is separated as:

- L1, energy;

- L2, materials and resources; and

- L3, off-site environment.

The evaluation parts above are recorded based on the scoring standards set of 1-5 for each at a stage form. 
Each part is given 1 point for stage 1-5 points for level five. For the result to be produced for the building as a whole, for each part score will be combined floor areas in an average, based on the ratio that is calculated for every segment. The grades are of 2 types, $1^{\text {st }}$ will be the score sheet, for every Q and L subgroups and 2nd is the evaluation outcome sheet for all field as bar graphs, star charts, and data of numerical form for $\mathrm{Q}$ (building performance and environmental quality) and LR (load reduction of the building). The instrument has presented a class of five parts, in terms of sustainability, grade $\mathrm{C}$ is considered as poor, average for grade $\mathrm{B} 2$, grade $\mathrm{B} \mathrm{p}$, grade $\mathrm{A}$, and excellent for grade $S \underline{12}$.

\subsection{Green Building Index (GBI)}

GBI was established by the Association of Consulting Engineers Malaysia (ACEM) and Pertubuhan Akitek Malaysia (PAM). The aim of introducing GBI is to monitor the Malaysia property industry to make the country more environmental friendly. It is planned to reassure sustainability in the built environment and increase the environment problems awareness $s^{15}$.

The aim of developing GBI is to recycle materials, save energy, resources, and to make sure that the building is in relation to the Malaysia climate, customs, and values also sustaining the environment at local and worldwide levels $\frac{16}{}$. GBI comprises of six (6) elements and the points that are allocated to each element, which includes:

GBI as Malaysia industry for building identifies that sustainable evaluation method as an important standard to support Sustainable Development in the built environment. Also wishes to increase awareness between designers, developers, planners, architects, engineers, also contractors, and public, about Sustainable Development concerns $s^{17}$.

\subsection{The Green Mark Method}

The Building and Construction Authority (BCA) Green Mark System was established in January 2005 as an enterprise to transform Singapore's industry of construction to sustainable one. It is planned to increase the awareness of environmental issues designers, developers, and builders for design and construction project and to encourage the built environment to be more environmental friendly.

BCA Green Mark is a sustainable building assessment method to analyze environmental effect and performance of a building. It is recommended and maintained by the National Environment Agency. It offers a complete framework aimed at evaluating environmental responsiveness and the building performance ${ }^{12}$. Five key criteria are used to award the buildings

- Water Efficiency

- Energy Efficiency

- Site Project Development and Management (Building Operation and Management for present buildings)

- Environmental Protection and Good Indoor Environmental Quality

- Innovation

There are points that are awarded for integrating environmental friendly features other than conventional practice. The evaluation classifies designs where particular objectives are met. The building will be more environmental friendly once it meets one or more objectives. The environmental friendliness of the building design will be indicated by the total number of points achieved.

The evaluation process comprises of an original evaluation which lead to the Green Mark award. Afterwards, buildings are necessary to be evaluated in every three years. The reason behind is to maintain the Green Mark building. The ascending order of the award for the buildings are Certified, Gold, Gold PLUS, and Platinum depend on the points that the building scored. In each category except the Innovation group, the building should have points that are at least minimum of $50 \% \frac{12}{}$.

\subsection{The VERDE System}

This is a Spanish way of assessing the buildings environmental performance. The system is used for new residential, educational, offices, commercial, hospitals, and hotels. Evaluations of the life cycle of a project can be done at different stages. There are three stages in the system which are: 
- HV1, the information found when ending the pre-design stage evaluation is planned to specify the possible future sustainable performance of the building.

- HV2, be before tenancy, the information found when pre-design, construction and commissioning stage come to an end, but in the design, and construction stage evaluation is planned to specify the possible sustainable performance of the building in future.

- HV3, evaluation at the process stage is planned to offer an objective and genuine sign of the real building performance and the grades will be used for certification of the building.

The method has an extensive variety of sustainable building matters, environmental loadings, indoor environment quality, release to air, resources exhaustion, local and regional influences, water and solid wastes, factors affecting building environment, social and economic aspects, and quality of service ${ }^{12}$.

The targets are categorized into two main forms: there are ones that are in numeric form and others that are labeled in text form. A value scale 0 to $\mathrm{p} 5$ is presented, where 0 represents the minimum acceptable performance, and 5 represents maximum performance and best practice attained using affordable cost and the best technology available.

The elements were calculated based on percentages which are shown in Figure 1, Indoor environmental quality has $100 \%$ which means the entire assessment tool considered that. $92 \%$ goes to energy efficiency, water efficiency, and material and resources. Then, sustainable site has $85 \%$, the rest of the elements are below $70 \%$. Land use and ecology has $64 \%$, while $57 \%$ is for service quality and innovation and design. Followed by Social aspect 50\%, Transport $42 \%$ also management $35 \%$. Regional priority and life cycle assessment both have $28 \%$, likewise, cultural aspect and economy aspect have $21 \%$ both and the and least among the elements is awareness $\%$ education which has only $7 \%$.

The most used elements found are indoor environmental quality, sustainable site, energy efficiency, water efficiency, and materials and resources. The importance of the 5 elements is as follows: -

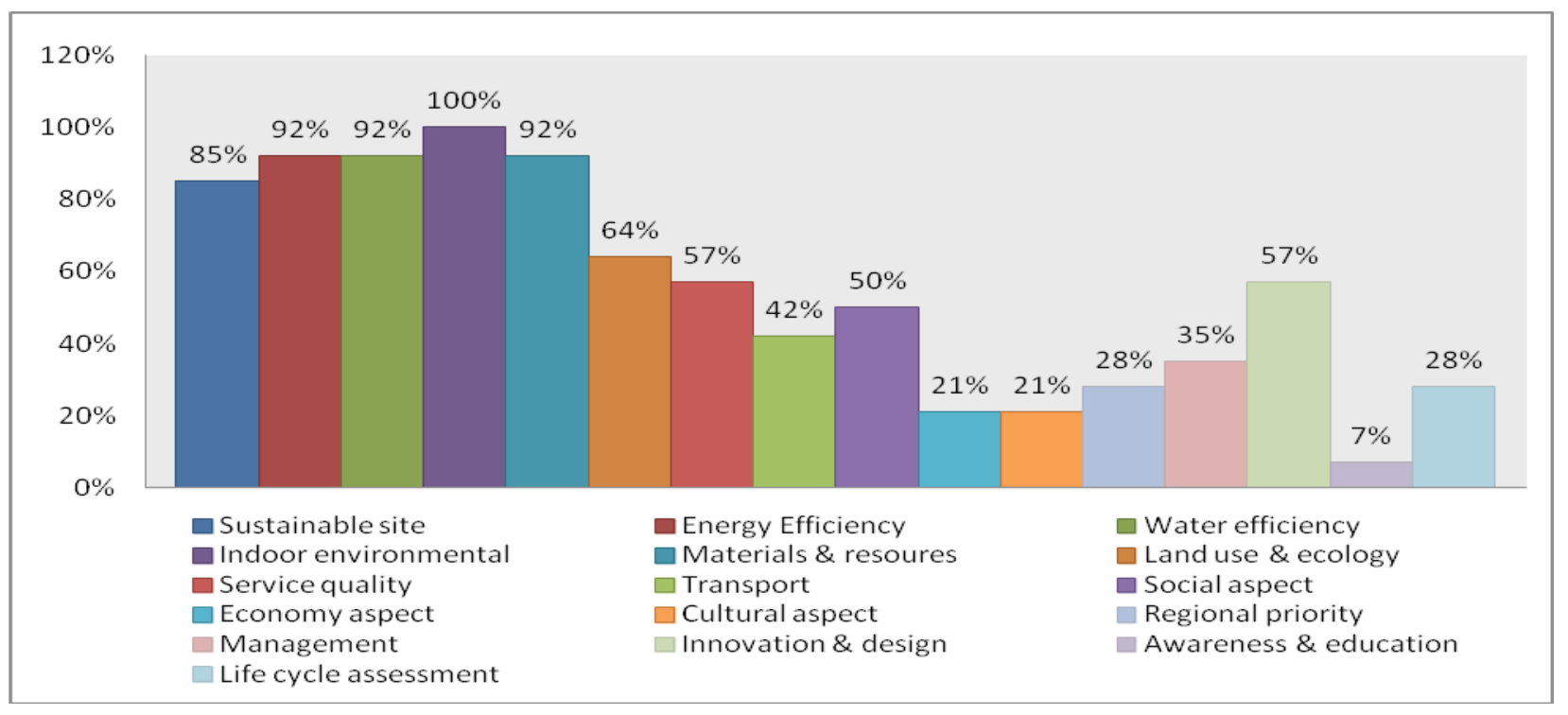

Figure 1. Percentage of sustainable elements used in different countries. 


\subsubsection{Indoor Environmental Quality}

Sustainable buildings are aimed to form a healthier, enjoyable, and useful work environment which offers them best likely conditions in terms of thermal comfort, access to natural ventilation, day lighting, and good indoor air quality and active control of the acoustic environment. The skills which is used to fulfill this criteria include material selection, maximize the use of natural day lighting, natural ventilation and maximize the use of operable windows, design building envelope and environmental systems in such a way that not only provide adequate ventilation and treat air temperature and, but also respect all of the environmental settings which distress human health and thermal comfort, including the indoor air velocity, temperature, and humidity, mean radiant temperature of interior surfaces ${ }^{18}$.

\subsubsection{Sustainable Site}

The aim is to develop only on suitable sites and to evade the environmental influences of locating on poorly selected sites. The sustainable design also preserves important environmental resources through a thorough inspection of every site along with put emphasis on design and construction process that reduces site negative effect which conserves and really restores or regenerates appreciated habitat, green space and associated eco-systems that are important to sustaining life. Some aspect should be taken into consideration to attain better comfort and lesser the energy bill include landscaping, building orientation, building form, building fabric, air infiltration, natural delighting and ventilation and passive solar heating and cooling ${ }^{18}$. For the site to be sustainable, building orientation, parking capacity, Greenery and Roof etc. need to be considered.

\subsubsection{Energy Efficient}

Energy efficient is to design energy efficient buildings that sustain the best environment for human occupancy while minimizing energy cost. The objectives of energy efficient buildings are to increase the levels of comfort for the occupants and cut down the use of energy (electricity, natural gas, etc) for lighting, cooling, and heating. Progression in energy efficiency is measured as any act accepted by a manufacturer or operator of energy products, that reduces use of energy per unit of production, without disturbing the level of production provided ${ }^{19}$. Under energy efficiency there is low energy, energy efficiency fittings and renewable energy which has several branches to be considered such as wind, biomass, hydroelectric, and geothermal.

\subsubsection{Water Efficiency}

In sustainable design is important to Manage of water and waste during the construction period up till demolition of the building. This feature follows the hydrological systems where the existing natural water is recycled. Maintenance of storm water, on-site penetration, and restoring of ground water using approaches that thoroughly follow natural systems should be emphasis. One of the significant features of this design is to lessen the pointless and wasteful use of filtered water on the site while improving recycling and reuse of water, as well as gray water, storm water, and harvested rainwater ${ }^{18}$. For water efficiency rain water harvest, water recycling, water efficient fittings etc. are to be considered.

\subsubsection{Materials and Resource}

This feature integrates the maximum use of re-usable, renewable, sustainably managed; bio-based materials along with identifying the means to lessen the extent of materials needed and reduce the quantity of waste produced through the implementation of a construction waste reduction plan ${ }^{20}$. Besides, a significant amount of energy (12 percent to 40 percent) can be saved if recycled materials are used for building construction ${ }^{21}$. Minimize the use of non-renewable construction materials and other resources such as energy and water through efficient engineering, design, planning and construction and effective recycling of construction debris. Maximize the use of recycled content materials, modern resource efficient engineered materials, and resource efficient composite type structural systems wherever possible. Maximize the use of re-usable, renewable, sustainably managed, biobased materials. Remember that human creativity and our abundant labor force is perhaps our most valuable 
renewable resource. The best solution is not necessarily the one that requires the least amount of physical work ${ }^{22}$.

\section{Conclusion}

The fundamental elements found in this research are indoor environmental quality, sustainable site, energy efficiency, water efficiency, and materials and resources. These five (5) fundamental elements are the backbone of sustainable design the will make a building comfortable for people to live in. If the indoor does not have good quality then the occupants will not be comfortable, so the sub elements such as ventilation, daylight, thermal comfort etc. should be considered in making indoor environment a qualitative one. If possible it should be done naturally by making use of passive energy so that the energy use in the building should be less or renewable to make the building energy efficient. The use of water should be minimal or it should be recycled by collecting, treating, and distributing potable water and the collection and treatment of wastewater for environmentally safe disposal back into waterways AIA ${ }^{10}$. In conclusion these five (5) elements should be used in every design so that it can reduce or eliminate the negative impact of buildings on the environment and occupants.

\section{References}

1. Green Buildings, High Performance Buildings, and Sustainable Construction: Does it Really Matter What We Call Them. 21 Vill Envtl L J. Available from: http://digitalcommons.law.villanova.edu/elj/vol21/iss1/1. Date Accessed: 21/02/2016.

2. Samiul Islam FA, Iftekharul Alam MM, Barua S. Investigation on the uses of steel as a sustainable construction material in Bangladesh. IJSEAS. 2016; 2(1):41-52.

3. Lechner N. Heating, Cooling, Lighting, Sustainable Design Methods for Architects. Canada 4th Ed. Hoboken, New Jersey: John Wiley and Sons, Inc.; 2015.

4. Parashar AK, Parashar R. Construction of an eco-friendly building using green building approach. International Journal of Scientific and Engineering Research. 2012; 3(6):1-7.

5. Khoshnava SM. Integration between sustainable design and constructability. APSEC-ICCER. In: Norhazilan Md.
Noor, Editor. Sustaining the World with Better Structures and Construction Practice. 2012. p. 1-5.

6. U.S. Green Building Council. An Introduction to the U.S. Green Building Council and the LEED Green Building Rating System. 2003. Available from: www.usgbc.org/ Resources/research.asp

7. Brundtl and Commission. Our common future. World Commission on the Environment and Development. London: Oxford University Press; 1987.

8. Enegbuma WI, Ali KN. A preliminary Critical Success Factor (CSFs) analysis of Building Information Modelling (BIM) implementation in Malaysia. Proceedings of the Asian Conference on Real Estate Sustainable Growth, Management Challenges; Thistle Johor Bahru, Malaysia. 2011 Oct 3-5.

9. Poston A, Emmanuel R, Thomson C. Developing holistic frameworks for the next generation of sustainability assessment methods for the built environment. In: Egbu C, Editor. Proceeding of 26th Annual ARCOM Conference, Leeds, UK, Association of Researchers in Construction Management; 2010 Sep 6-8. p. 1487-96.

10. AIA Continuing Education Guidelines for Approving AIA/CES Sustainable Design Courses. Available from: http://www.aia.org/aiaucmp/groups/aia/documents/pdf/ aias076887.pdf

11. Larsson N. International Initiative for a Sustainable Built Environment. SB Tool for 2015. Available from: http://www. iisbe.org/system/files/SBTool\%20Complete\%2004May15. pdf. Date Accessed: 2015.

12. Darus ZM, Hashim NA, Salleh E, Haw LC, Abdul Rashid A, Abdul Manan SN. Development of rating system for sustainable building In Malaysia. WSEAS Transactions on Environment and Development. 2009; 5(3):260-72.

13. Green Building Council of Australia (GBCA). The Value of Green Star - A Decade of Environmental Benefits. Available from: http://www.gbcsa.org.za/wpcontent/ uploads/2013/06/The_Value_of_Green_Star_A_Decade_ of_Environmental_Benefits.pdf

14. Alex M. Green Star: What's in it for us? Electrical Engineering Group Leader Lend Lease design. Available from: http://nesma.org.au/images/edusafe/2009-greenStar. pdf

15. Chin LH. Energy efficiency in FKE`s laboratories [Unpublished Degree thesis]. University Technology Malaysia (UTM); 2012.

16. Mun TL. The development of GBI Malaysia (GBI). PAM/ ACEM. 2010; 15. 
17. GBI Malaysia, Buildings certificates criteria, GBI Malaysia, 2010, 15, PP.1-35.

18. Lipu MSH, Jamal T, Karim TF. An approach towards sustainable energy performance by green building: A review of current features, benefits and barriers. International Journal of Renewable and Sustainable Energy. 2013; 2(4):180-90.

19. Ahsan T. Passive design features for energy-efficient residential buildings in tropical climates: The context of Dhaka, Bangladesh. KTH, Department of Urban Planning and Environment Division of Environmental Strategies Research; Kungliga Tekniska Hogskolan. 2009.
20. Thormark C. The effect of material choice on the total energy need and recycling potential of a building. Building and Environment. 2006; 41(8):1019-26.

21. UNEP (United Nations Environmental Programme). Green Economy: Pathways to Sustainable Development and Poverty Eradication. Available from: http://www.unep.org/ GreenEconomy/Portals/93/documents/Full_GER_screen pdf

22. Sirija M. Application of green technologies in architecture. Recent Research in Science and Technology. 2014; 6(1):659. 